\title{
12 Integrated pest management in Southern Africa
}

\author{
Approaches and enabling policy issues
}

\author{
Mark D. Laing and Hussein Shimelis
}

\section{Introduction}

\section{Crop losses and environmental damage in Africa due to pests}

The United Nations Food and Agriculture Organization has defined "pest" as any organism that damages crops or the environment (FAO Glossary of Terms 2010). It includes invasive weeds, parasitic weeds, insects, nematodes, pathogens and feral animals. Across Africa pests such as the fall armyworm devastates cereal crops, rampant aquatic weeds clog water systems and thorny mesquite trees have overrun millions of hectares of agricultural lands in arid and semi-arid regions. Preharvest crop losses caused by pests are estimated at $45 \%$, whereas postharvest losses of grain crops in storage are typically 40-70\%. Possibly the most sustainable way to enhance food security in Africa would be to control the primary pre- and postharvest pests of food crops. Pest control in Africa has largely depended upon cultural control measures and agrochemicals. Cultural control alone does not cope with a scaling of the agricultural systems or the intensification of production that is required to feed the burgeoning human population in Africa. Climate change has also caused rapid shifts in pest populations in response to changing natural ecosystems in Africa. Therefore, there is a need for an integrated pest management (IPM) approach that is effective, adaptable and scalable. The objective of this chapter is to highlight the potential of IPM to enhance food security and crop productivity. Policy aspects are identified that could enhance the effective implementation of IPM in Africa.

\section{Integrated pest management (IPM)}

IPM is the integration of various pest control methods such as host-plant resistance, cultural methods, agrochemicals and biocontrol agents for the control of pests affecting crops or the environment.

\section{Host-plant resistance}

The use of pest resistant crop varieties is potentially the cheapest and most environmentally friendly approach for pest control. However, it requires the longterm investment of resources (e.g., research funding, genetic resources, capacity 
development and research capacity) in public and private breeding programmes that are demand-driven and generate varieties that meet farmers' preferences, as well as improved pest resistance. It also requires a downstream value chain to deliver the new, pest-resistant varieties to the farmers that need them.

\section{Cultural methods}

These include crop rotation, cover cropping, trap-cropping, soil fertilization, hand weeding and the push-pull approach (the use of trap crops to attract pests away from the main crop). These approaches may be effective but require intensive training by extension services, the commitment of substantial resources of land, labour and funds and collective action by communities of farmers (Hearne, 2009). Cultural control measures usually provide variable results. These are some of the factors that have resulted in a relatively poor adoption of most cultural control methods on their own (Parsa et al., 2014).

\section{Agrochemicals}

Agrochemicals have been crucial for crop protection for the last 70 years, making a significant contribution to world food production. Across Africa they are still the basis for crop protection on most commercial farms and many smallscale farms. However, they face a number of limitations to their role in the control of pests globally, especially in the future. In some cases, there is no effective agrochemical to control a particular pest currently, e.g., there are no fungicides currently available to control the Fusarium species. In other cases, target pests have evolved resistance to effective agrochemicals; e.g., grey mould (Botrytis cinerea) to the fungicide benomyl (Hahn, 2014). There are also strong laws and control mechanisms to prevent residues in foodstuffs that has resulted in the restriction of use of many agrochemicals. For example, the use of guazatine for the control of sour rot of fruit and vegetables was effectively banned in the EU in 2016 (EU Regulation, 2015/1910). Evidence that some agrochemicals were damaging the environment led to their global withdrawal (MeBr), while others have been withdrawn because of their extreme toxicity, and others for their carcinogenicity (Shukla and Arora, 2001; Lin et al., 2014) or their anti-androgenic activity (Uzumcu et al., 2004).

A major consideration for pest management in the long term is the extreme costs of developing new agrochemicals. Only 1 in 140,000 molecules are successfully developed into agrochemicals. The full costs were estimated to exceed US $\$ 286$ million per new agrochemical in the period 2010-2014 (McDougall, 2016). Registration of agrochemicals in Africa is challenging because the costs of applying for permits for the pesticide are high relative to the potential market available in each country, except for export crops. Hence, the agrochemicals available to small-scale farmers in Africa are often older products that are cheap. However, relatively few small-scale farmers can afford to buy agrochemicals or their application equipment. Safety is also an issue because the hot and humid conditions occurring frequently in Africa make it hazardous to wear effective 
safety equipment (Mokhele, 2011). Extension services in most of Southern Africa are limited, making it challenging to inform the millions of small-scale farmers of the technical aspects of agrochemicals: targets, dose, frequency, timing, mixing and safety aspects. Few small-scale farmers are technically literate, which inhibits the use of information pamphlets. Information transfer then requires face-to-face extension support services or the use of mobile application technologies, using local languages.

\section{Biocontrol}

The development of biocontrol agents starts with the isolation and screening of insects, fungi, bacteria, viruses or nematodes for the control of a target pest. The chosen strain of the biocontrol agent is then manufactured, formulated and sold to farmers to treat their crops. Commercial biocontrol agents have to be applied repeatedly to the crop of concern; e.g., application of selected strains of Trichoderma species to seeds of many crops to control damping off of seedlings by Rhizoctonia solani (Yobo et al., 2004). Their relatively low costs and safety make them an attractive option for Africa. However, most of them have a limited shelf life (typically six to 24 months at $20^{\circ} \mathrm{C}$ ). Cold storage in a deep freezer can provide for indefinite storage, but this equipment is usually absent at agro-dealers and small-scale farmers. The development and commercialization of a biocontrol product follows a value chain with defined steps and key participants (Figure 12.1).

The development of commercial biocontrol agents is relatively fast and cheap, compared to agrochemicals, an estimated US $\$ 5$ million vs. US $\$ 250$ million per product. However, the relatively few commercial biocontrol agents that have been developed in Africa, largely come from South Africa and Kenya (Barratt et al., 2018). Use of a biocontrol agent requires a thorough understanding of the product and the target pest. This requires competent and widely distributed extension services.

\section{IPM - integrating the components}

IPM involves the use of two or more crop protection methods, integrated for superior pest management. Ideally, IPM involves several control measures, integrated to complement each other. A model of IPM involving the integrated control of Striga species affecting cereals and cowpea is shown in Figure 12.2 The parasitic weeds Striga asiatica and S. hermonthica in cereal crops and Striga gesneroides in cowpea, cause losses of up to $80 \%$ in key food crops, especially in dry regions of Africa with low-fertility soils. Effective management of Striga species usually requires the integration of a spectrum of IPM measures (Hearne, 2009; Mangani et al., 2011; Shayanowako et al., 2018).

Integrated application of the four components of IPM requires positive and enabling policies. African governments need to commit to developing the value chain of IPM that will allow for the development, registration and deployment 


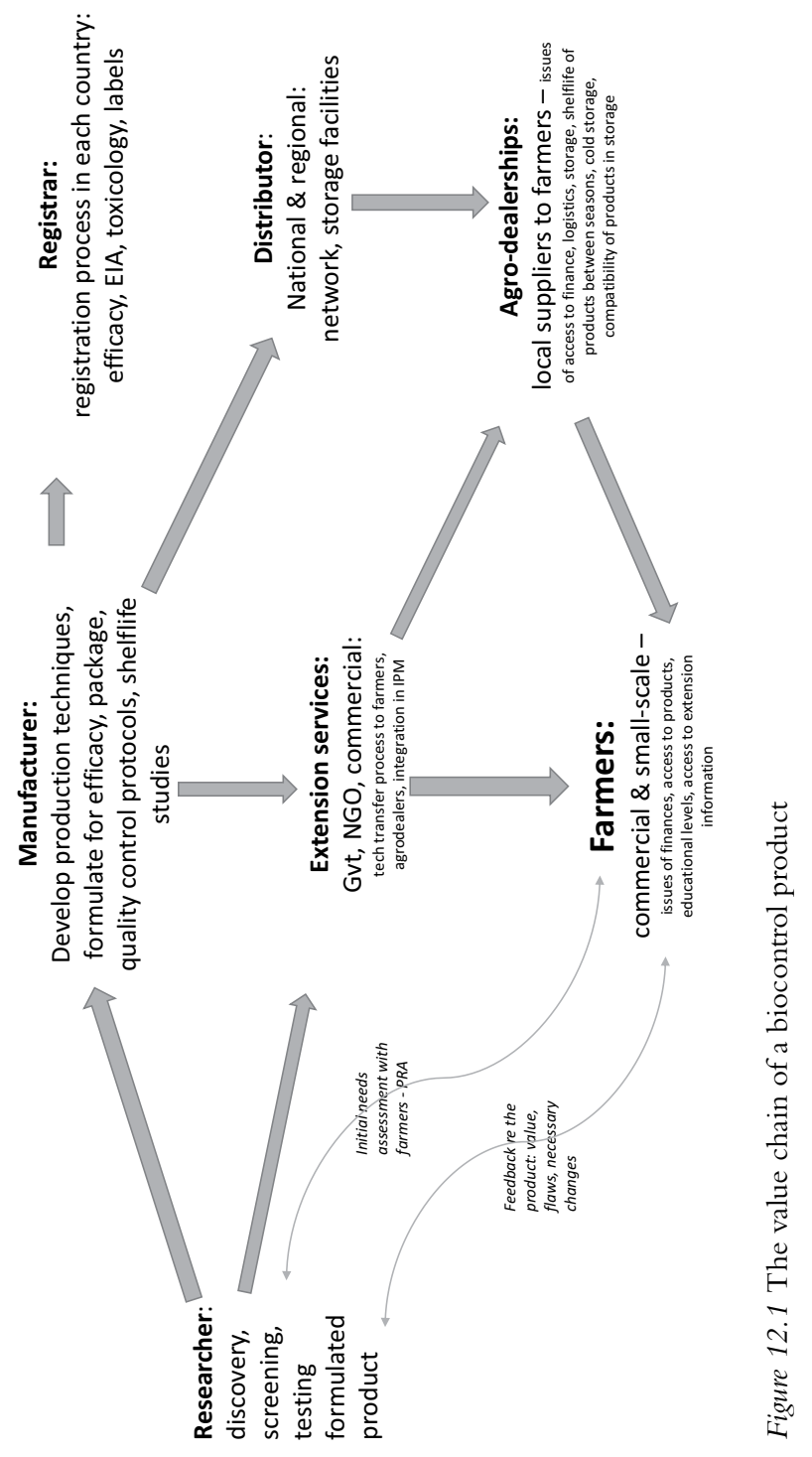



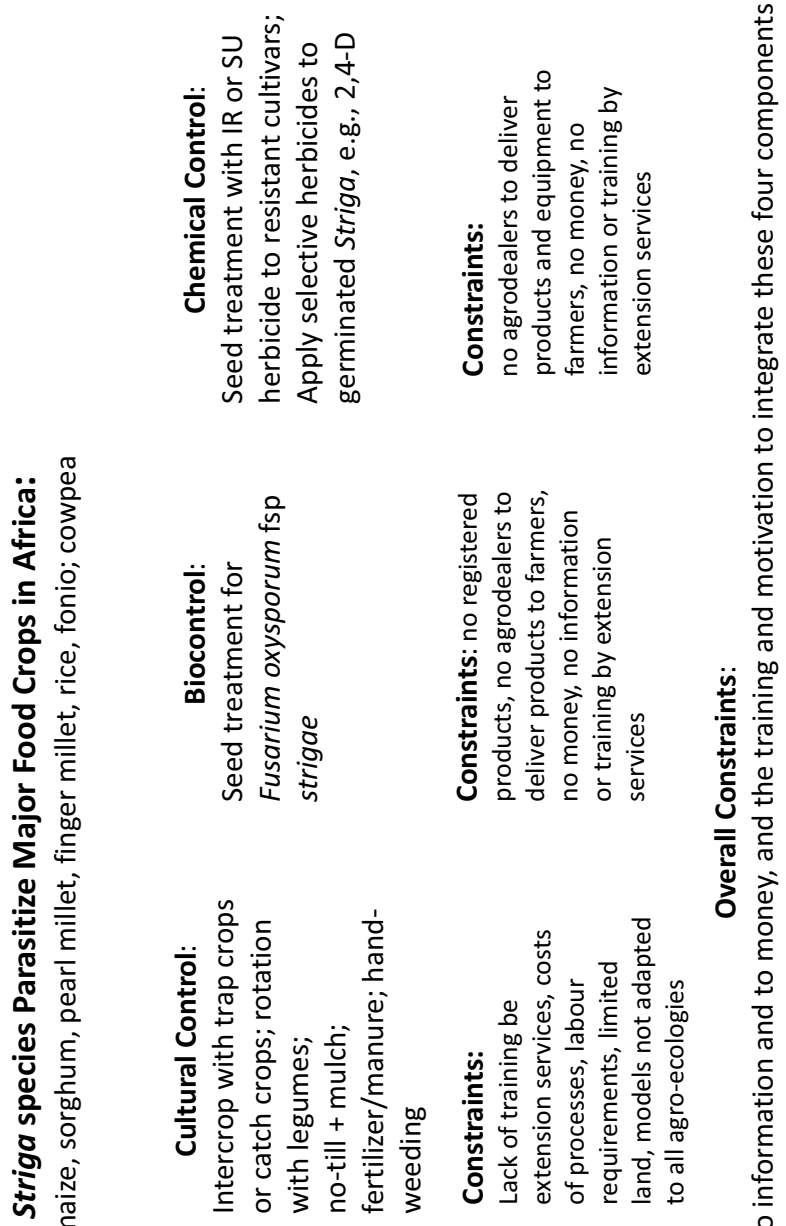

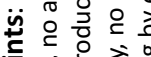

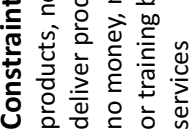

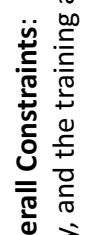

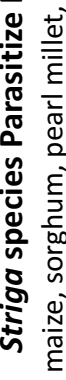
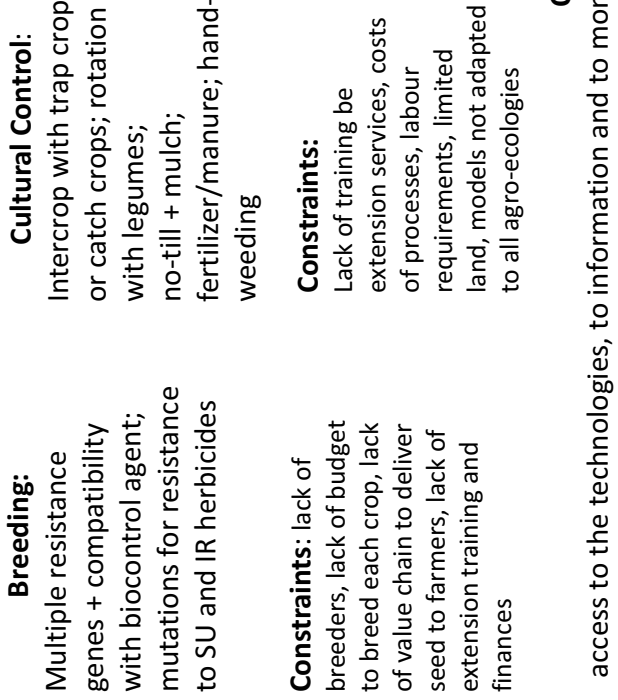

ठั ญे

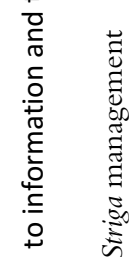

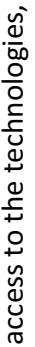

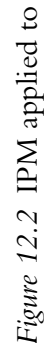


of key technologies, together with the critical technology transfer process by extension services, working with farmers. This will require the deployment of innovative communication technologies, such as the provision of video-based training shared with farmers using mobile technology. Farmers also need access to credit to be able to purchase the components of IPM: seeds, fertilizers, agrochemicals, biocontrol agents and application equipment. The Grameen Bank in Bangladesh pioneered a model for microfinancing of small-scale farmers (McWha and Willows, 2016).

\section{Policy issues affecting access to improved seed, agrochemicals and biocontrol agents}

\section{Lack of regional harmonization}

Harmonization issues affect the previous components of IPM. Given the time and cost taken to develop new crop varieties, agrochemicals or biocontrol agents, especially where the key pests affect entire regions, there is a critical need for regional harmonization in the registration of new crop varieties, agrochemicals and biocontrol agents. The African Union has published draft policies on the harmonization of pesticides (and biocontrol agents), but it has not passed the draft as a functional act (AU-IBAR, 2016). Until the Act is passed and enforced regionally, the registration processes will remain on a country-bycountry basis. This is a particularly serious problem for poorer countries that usually cannot afford to employ specialist scientists to manage these processes. Similarly, the costs of development and registration, and the delays in commercializing new varieties, agrochemical or biocontrol agents, mean that these products are usually not registered in poor countries unless effective regional harmonization policies are in place. In some cases, such as the East African Community, harmonization policies have existed since 1999, but are not implemented at a country level.

\section{Lack of resources for multiplication of insects, fungi and viruses}

Across Africa, there are few research establishments that can consistently isolate, identify, store and maintain biocontrol agents, be they insects or microbes. This is a major barrier to the widespread development of biocontrol agents. There is an even greater shortage of companies that can manufacture biologicals on a large scale, register and market them so that biocontrol agents become available to all the farmers of Africa. Much of the current academic research on biocontrol is unlikely to reach the farmer because few of the research teams are working with industry partners that are committed to commercializing a wide range of novel biocontrol agents. This includes researchers at the National Agricultural Research Systems, the Consultative Group for International Agricultural Research centres and at universities across Africa, who may discover 
many potentially useful biocontrol agents, but unless they can be commercialized, these biocontrol studies are merely an academic exercise. A powerful policy change would be if funders and national assessors reviewing project proposals in the field of biocontrol required the researchers to include a full value chain that could deliver products into the hands of farmers (Figure 12.1).

\section{Costs and time taken to register products}

Most local seed companies, agrochemical distributors and biocontrol companies that have developed in Africa are relatively small, start-up companies. As start-up companies, they usually have a limited access to capital and their survival depends upon securing a stable cashflow before their start-up capital is spent. However, registration requirements are becoming increasingly stringent, take longer and cost more. As a result, most of the indigenous start-up companies are unable to survive this barrier. If African farmers are to have access to a wide range of modern agrochemicals and biocontrol agents, then there is a need for African governments to support indigenous crop protection companies with tax breaks and access to capital, specifically so they can complete the registration processes to international standards.

\section{Efficacy trials}

For both agrochemicals and biocontrol agents, there is a registration requirement to show efficacy in most countries. However, there is also a demand for separate registration for the same pest on every crop that the pest affects, even with a polyphagous pest or disease, e.g., twin spotted red spider mite or Sclerotium rolfsii, with more than 100 hosts each. However, the interaction is between the control agent and the pest, and the crop plays little part. This creates a massive barrier to registration of products for minor crops: in most cases, it is not financially viable to register a product on the minor crop because the potential income is less than the costs of registration.

\section{Toxicology testing}

While clearly these are essential, the toxicological testing requirements create a huge financial barrier for small companies. One barrier is that there are no International Organization for Standardization accredited toxicological laboratories in Africa, with the result that all toxicological testing has to be undertaken in Northern Hemisphere countries, at a cost that small start-up companies in Africa cannot afford. This requirement alone raises the barrier to development of locally registered products in Africa to an unreachable level. This means that only major agrochemical companies, or a few established biocontrol companies, can afford to develop a full spectrum of new agrochemicals and novel biocontrol agents for IPM programmes in selected countries in Africa, usually for the protection of cash crops only. 


\section{Bioprospecting policies}

The Convention on Biological Diversity (CBD) was passed by the United Nations in 1993, and was followed by the Nagoya Protocol of 2010 (United Nations, 2010). These regulations directly affect the development of novel biocontrol agents. The assumption is that indigenous organisms were all part of indigenous knowledge systems (IKS) and the genetic resources of one country, and therefore the company that develops a biocontrol agent must pay a royalty to the local community to whom the IKS and generic resources "belonged" (Access and Benefit Sharing - ABS). However, there is no evidence that either microbes or insects were ever used in Africa to control pests. Second, many of the microbes used as biocontrol agents, such as Trichoderma sp., are universal. Therefore, it is not clear what country or region should benefit from a newly discovered strain of Trichoderma, for example. Third, it is not clear who the "community" is who should benefit from the royalties within a country, nor are there sound administrative processes in place in much of Africa to manage these payments (Chennels, 2010; Cock et al., 2010; Millum, 2010).

\section{Summary}

Farmers in Africa have previously depended on cultural control and agrochemicals for crop protection. However, the future of agriculture in Africa will depend on controlling pests with an integration of these measures, combined with demand-led plant breeding and biocontrol agents. The primary policy issues affecting the development and deployment of IPM include the need to:

- Develop appropriate and affordable regulatory measures for novel seeds, agrochemicals and biocontrol agents

- Ensure the actively enforced harmonization of agricultural registration requirements on a regional basis in Africa

- Create enabling environments to promote the development and distribution of locally bred crop varieties and commercial biocontrol agents

- Resolve issues associated with the Nagoya Protocol and the CBD to avoid stopping the development of novel biocontrol agents

- Support agronomic approaches that promote ecosystem services to limit pest damage as outlined in the chapter in this book.

A range of enabling policies and long-term financial commitments by African governments are needed to accelerate the development and uptake of new crop cultivars and biocontrol agents and access to novel agrochemicals. Access to these technologies, combined with appropriate training and access to credit facilities, are essential. Furthermore, there is a critical need for long term investments by African governments in capacity development of scientists working on IPM, in demand-driven research, combined with the mobilization of extension services and stakeholder engagement in IPM. 


\section{References}

AU-IBAR. (2016) Draft Policy for the Harmonization of Pesticides Registrations in Africa https://www.google.com/search?q=harmonization+policies+African+union+pesticides\& rlz=1C1ZKTG_enZA698ZA701\&oq=harmonization + policies +African+union + pesti cides\&aqs=chrome..69i57.15655j1j4\&sourceid=chrome\&ie=UTF-8. Access 20190301.

Barratt, B.I.P., Moran, V.C., Bigler, F. and van Lenteren, J.C. (2018) The status of biological control and recommendations for improving uptake for the future. Bio Control 63: 155-167.

Chennels, R. (2010) Towards global justice through benefit-sharing. Hastings Centre Report 40: 3 .

Cock, M.J.W., van Lenteren, J.C., Brodeur, J., Barratt, B.I.P., Bigler, F., Bolckmans, K., Consoli, F.L., Haas, F., Mason, P.G. and Parra, J.R.P. (2010) Do new access and benefit sharing procedures under the convention on biological diversity threaten the future of biological control? Bio Control 55: 199-218.

FAO Glossary of Terms (2010). In: Guide to Implementation of Phytosanitary Standards in Forestry http://www.fao.org/3/i2080e/i2080e08.pdf.

Hahn, M. (2014) The rising threat of fungicide resistance in plant pathogenic fungi: Botrytis as a case study. Journal of Chemical Biology 7: 133-141.

Hearne, S.J. (2009) Control - the Striga conundrum. Pest Management Science 65: 603-614.

Lin, C.H., Chou, P.H. and Chen, P.J. (2014) Two azole fungicides (carcinogenic triadimefon and non-carcinogenic myclobutanil) exhibit different hepatic cytochrome P450 activities in medaka fish. Journal of Hazardous Materials 277: 150-158.

Mangani, E.I., Ibrahim, A. and Ahom, R.I. (2011) Integrated management of parasitic plant Striga hermonthica in maize using Fusarium oxysporum (mycoherbicide) and post-emergence herbicide in the Nigerian savanna. Tropical and Subtropical Agroecosystems 14: 731-738.

McDougall, P. (2016) The costs of new agrochemical product discovery, development and registration in 1995, 2000, 2005-8 and 2010-2014. R\&D expenditure in 2014 and expectations for 2019. A Consultancy Study for CropLife International, CropLife America and the European Crop Protection Association https://croplife.org/wp-content/uploads/2016/04/ Cost-of-CP-report-FINAL.pdf. Accessed 20190301.

McWha, J. and Willows, G. (2016) MAF05: The fight against poverty: Review of the applicability of the Grameen bank model in South Africa. In: 2016 Southern African Accounting Association National Teaching and Learning and Regional Conference Proceedings, pp. 357-369. ISBN number: 978-0-620-74761-5.

Millum, J. (2010) How should the benefits of bioprospecting be shared? Hastings Centre Report 40: 24-33.

Mokhele, T.A. (2011) Potential health effects of pesticide use on farmworkers in Lesotho. South African Journal of Science 107(7-8) Art. \#509, 7 pages.

Parsa, S., Morse, S., Bonifacio, A., Chancellor, T.C.B., Condori, B., Crespo-Perez, V., Hobbs, S.L.A., Kroschel, J., Ba, M.N., Rebaudo, F., Sherwood, S.G., Vanek, S.J., Faye, E., Herrera, M.A. and Dangles, O. (2014) Obstacles to integrated pest management adoption in developing countries. Proceedings of the National Academy of Science, USA 111: 3889-3894.

Shayanowako, A.T., Laing, M., Shimelis, H. and Mwazingezi, L. (2018) Resistance breeding and biocontrol of Striga asiatica (L.) Kuntze in maize: A review. Acta Scandinavica, Section BSoil and Plant Science 68: 110-120.

Shukla, Y. and Arora, A. (2001) Transplacental carcinogenic potential of the carbamate fungicide mancozeb. Journal of Environmental Pathology, Toxicology and Oncology 20: 127-131.

United Nations. (1993) Convention on biological diversity (1993) with annexes, concluded at Rio de Janeiro on 5 June 1992, Vol 1760 (30619). United Nations Treaty Series. 
United Nation. (2010) The Nagoya protocol on access to genetic resources and the fair and equitable sharing of benefits arising from their utilization (ABS) to convention on biological diversity https://www.cbd.int/abs/about. Accessed 20190301.

Uzumcu, M., Suzuki, H. and Skinner, M.K. (2004) Effect of anti-androgenic endocrine disruptor vinclozolin on embryonic testis cord formation and postnatal testis development and function. Reproductive Toxicology 18: 765-774.

Yobo, K.S., Laing, M.D., Hunter, C.H. and Morris, M.J. (2004) Biological control of Rhizoctonia solani by two Trichoderma species isolated from South African composted soil. South African Journal of Plant and Soil 21: 139-144. 